\section{ADMA}

Jurnal Pengabdian dan Pemberdayaan Masyarakat
Vol.1, No.1, June 2020, pp. 41-46

Doi: $x x x X X X X X$

\title{
Penambahan Omzet Usaha Jasa Penjahit Kebaya
}

\author{
Luh Putu Safitri Pratiwi ${ }^{1}$, Ni Putu Nanik Hendayanti ${ }^{2}$, I Ketut Putu Suniantara ${ }^{3}$ \\ putu safitri@stikom-bali.ac.id ${ }^{1}$, edwar.ridwan@stikom-bali.ac.id², nanik@stikom-bali.ac.id ${ }^{3}$
}

1,2,3 Institut Teknologi dan Bisnis STIKOM Bali

\section{Article History:}

Received:

Revised:

Accepted:

Keywords: marketing, sewing

\begin{abstract}
Good marketing is one of the important things in the development and addition of income in entrepreneurship. The problem faced in the business of sewing clothes is that partners are not too focused on marketing management. Partners rely more on conventional marketing systems, even though the new location of the partner services business is not too strategic. This causes the field of business is difficult to be recognized by the wider community so that it becomes an obstacle in developing its business. The purpose of this activity is to provide solutions to the problems being faced, namely by implementing marketing management using Facebook pages. With the socialization and marketing management training, it is expected to be able to add insight into the actors in utilizing the internet as an online promotion media to introduce their business fields to the wider community in increasing their business income. The result of this activity was that the Partners were very enthusiastic, both from socialization to evaluation. Assistance with the use of the Facebook pages application is expected to continue to be used in a sustainable manner
\end{abstract}

\section{Pendahuluan}

Menjalankan usaha jasa jahit pakaian kala ini masih menjanjikan, walaupun sekarang banyak produksi pakaian jadi, jasa jahitan tetap dibutuhkan konsumen. Karena ada beberapa risiko pembelian baju jadi yang biasanya kurang diterima oleh konsumen. Misalnya konsumen yang memiliki postur tubuh berbeda dengan standar orang pada umumnya (Berlianti,2017), seperti terlalu kurus atau terlalu gemuk. Pakaian jadi pabrikan meski memiliki model dan bahannya cukup bervariasi dan harganya pun lebih murah dibandingkan dengan memakai jasa penjahit, tapi tidak semua pakaian yang sudah jadi sesuai dengan badan konsumen. Oleh karena itu, usaha Jasa jahitan akan tetap dicari oleh konsumen yang meiliki postur tubuh terlalu kurus atau terlalu besar seperti ini. Kadangkala produksi pabrik pakaian jadi menggunakan model serta bahan baju tertentu yang kurang sesuai kalau dipakai dari hasil jahitan biasa. contohnya seperti pakaian tradisional misalnya pakaian adat (kebaya), bahan brukat, jas, kain tenun dan lain-lain. Ni Ketut Meriawati Salah satu Penjahi kebaya tradisional khas Bali. jenis jasa produksi mitra berupa jahit kebaya model kutubaru, modern berupa modifikasi tile, kemeja, kebaya anak, kamen jadi, dan lain-lain. Sebelum menjadi industry rumah tangga mitra pernah mengontrak tempat di Kota Gianyar pada taun 2014 mulai banyak peminat.

Pada akhir tahun 2016 mitra mengalami kendala mengenai biaya kontrakan di areal tersebut mengalami kenaikan dan mahal. Hal ini menyebabkan mitra berinisiatif untuk memulai 
usahanya di rumah mitra sendiri. Pindahnya lokasi menyebabkan konsumen yang tadinya banyak menjadi berkurang karena lokasi yang sekarang dan jauh. Konsumenyang menggunakan jasa mitra jumlahnya tidak menentu untuk melakukan jait kebaya tiap bulannya. Pada saat ramai pelanggan, mitra biasanya bisa menelesaikan jaitan 10 sampai 15 potong satu harinya. Untuk jahitan kebaya model kutubaru biasanya dibandrol dengan harga 50.00060.000, Model modifikasi dari arga 80.000-100.000. Hal ini menyebabkan bidang usahanya sulit dikenal oleh masyarakat luas sehingga menjadi kendala dalam mengembangkan usahanya.Kegiatan ini bertujuan utuk memberikan solusi mengenai permaslahan yang sedang dihadapi yaitu dengan menerapkan manajemen marketing menggunakan media internet (online). Berdasarkan hasil pengumpulan informasi dan permasalahan, maka diketahui situasi mitra ditunjukkan oleh Tabel 1 di bawah ini:

Tabel: 1 Situasi Mitra

\begin{tabular}{|l|l|l|}
\hline No & Uraian & Keterangan \\
\hline 1 & Hasil produksi & $\begin{array}{l}\text { Kebaya kutubaru, kebaya modern, kebaya anak, } \\
\text { kamen jadi, kemeja }\end{array}$ \\
\hline 2 & Produksi & Jumlah produksi tidak menentu \\
\hline 5 & Pemasaran & $\begin{array}{l}\text { Lokasi yang baru kurang strategis sehingga } \\
\text { pemasaran yang tidak terlalu luas dan pelanggan } \\
\text { mitra disekitar tempat tinggalnya }\end{array}$ \\
\hline
\end{tabular}

Usaha jahitan kebaya "Kartika Sari Kebaya" yang dimiliki mitra dapat dilihat pada Gambar 1 di bawah ini:

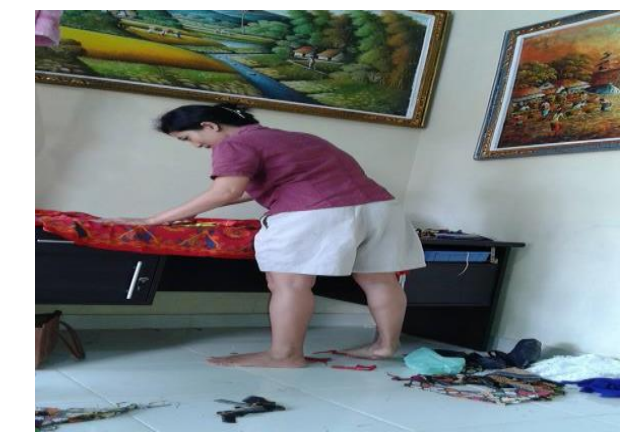

Gambar 1: Proses Produksi Kebaya

\section{Metode}

Sebagai kegiatan awal akan dilakukan Sosialisasi kepada mitra berkaitan dengan kegiatan pengabdian masyarakat yang akan dilakukan. Dalam sosialisasi akan diberitahukan target dan tujuan kegiatan kepada Mitra. Selain itu, akan dibahas juga mengenai pengelolaan usaha terutama mengenai pengelolaan keuangan sebagai awalan pembahasan sebelum dilakukan pelatihan. Persiapan pelatihan dilakukan berkaitan dengan materi dan aplikasi yang akan diberikan. Penyaji mengambil contoh kejadian-kejadian yang sederhana tapi perlu pencacatan, seperti pembayaran hutang piutang yang dilakukan secara cicilan, pengambilan barang dagangan yang pembayaran juga dilakukan dengan cicilan.Dari kejadian sederhana itu penyaji mebuat catatan berupa bukti transaski kuitansi, bukti pembayaran dan faktur penjualan. 
Pelatihan pengelolaan keuangan, manajemen pemasaran, dan manajemen mutu dilaksanakan selama satu hari. Peserta yang mengikuti pelatihan oleh dua orang yaitu pemilik usaha, beserta satu karwayan yang mempunyai tanggung jawab untuk mengelola usaha ini. Evaluasi kegiatan akan dilaksanakan setelah mitra menggunakan aplikasi pengelolaan keuangan tersebut dalam periode tertentu, kemudian dilanjutkan dengan pelatihan manajemen pemasaran, dan manajemen mutu berupa pelabelan.

Pelaksanaan pendampingan dilakukan secara individual pada mitra waktunya disesuaikan dengan kesepakatan antara permintaan mitra dan tersedianya waktu yang longgar dari tim pelaksana Adapun rangkaian kegiatan yang akan dilakukan dapat dilihat pada Gambar 2.

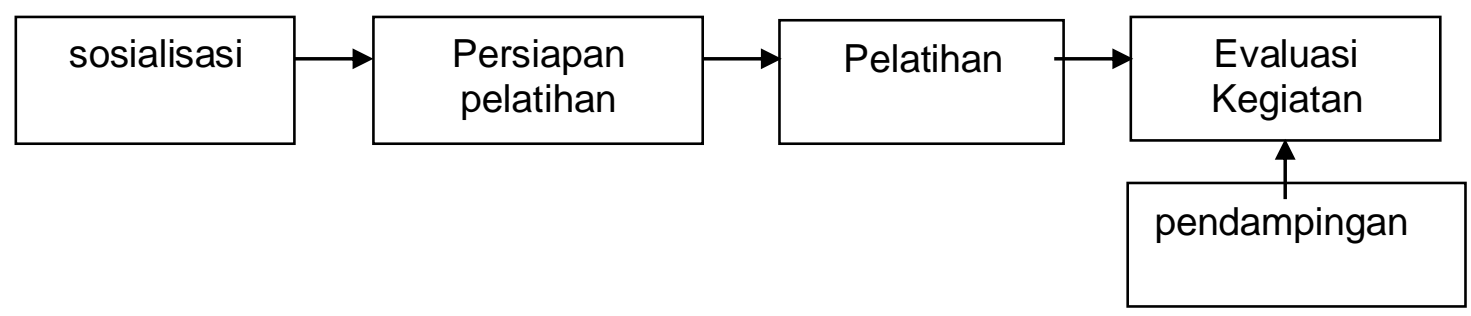

Gambar 2: Rangkaian Kegiatan

\section{Hasil}

Kotler dan Armstrong (2013) : Pemasaran online/online marketing/ internet marketing menggambarkan usaha perusahaan untuk memasarkan produk dan jasa, serta membangun hubungan dengan pelanggan melalui internet. Kegiatan pengabdian kepada masyarakat ini dilakukan dengan menggunakan metode penyuluhan., Mitra juga memerlukan pelatihan tentang pemasaran menggunakan media online untuk memperluas jangkauan pemasaran produk mitra yang akan di bahas pada rencana tahap berikutnya. Pelatihan ini dilaksanakan pada 30 Desember 2019 pada pukul 11.00-13.00 WITA.

Melalui pemasaran secara online diharapkan mereka dapat meningkatkan jumlah dan jasa yang dapat dijual sehingga dapat menghasilkan keuntungan yang maksimal dan balik modal yang cepat. Selama ini penjualan jasa dilakukan hanya dengan pemasaran offline dengan customer datang langsung ke rumah mitra. Memang mitra memanfaatkan media sosial facebook dan instagram untuk memperdagangkan barang dagangan mereka, tetapi belum ada yang menggunakan Facebook Pages untuk memperkenalkan barang dagangannya kepada khalayak ramai. Dalam kesempatan ini, kami memberikan tutorial pembuatan akun Facebook Pages dan memperagakan cara membuat Facebook Pages. Sebagai langkah awal untuk membuat Facebook Page (Admin,2016), sebelumnya login lebih dahulu ke Facebook menggunakan akun pribadi mitra. Klik option dan pilih menu Buat Halaman. 


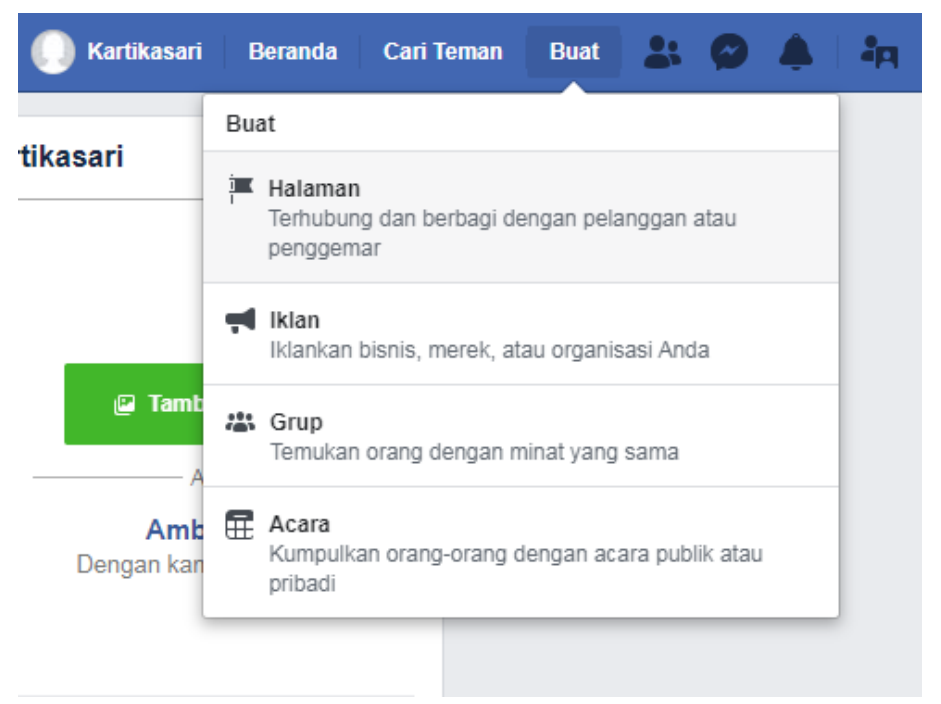

Gambar 3: Membuat Facebook Page

Setelah itu, pilih jenis Facebook Page yang relevan dengan kepentingan bisnis mitra Gambar. Setelah setuju, maka klik dan muncul lah menu "Pilih Kategori". Jika tidak ada kategori yang sesuai, maka cara termudah adalah mencari kategori lain yang hampir sama dengan kategori yang diinginkan.

Setelah memilih kategori, langkah selanjutnya yakni memilih nama untuk Facebook Page. Ada baiknya memilih nama yang masih berkaitan dengan jasa yang diberikan untuk membuat Facebook Page ini. Hal tersebut akan semakin tepat apabila nama Facebook Page mudah dihafal dan diingat. Langkah selanjutnya adalah dengan memasang/mengunggah foto profil Facebook Page. Foto profil ini akan muncul setiap mitra melakukan posting dan juga komentar yang dibuat oleh Facebook Page. Foto juga akan muncul pada tampilan muka Facebook Page Anda sendiri. Agar pengikut Facebook mengerti bisnis yang dijalankan, alangkah baiknya memasang foto profil logo bisnis atau headshot dari orang-orang yang banyak dikenal oleh publik. Gambar yang diunggah pun harus mempunyai ukuran dan proporsi persegi yang tepat. Jika memaksakan mengunggah gambar dengan proporsi dan ukuran yang tepat, foto profil Facebook Page akan terpotong dan hal tersebut menutupi identitas bisnis. Untuk itu, sesuaikan proporsi ukuran yang bisa diedit dengan media untuk mengubah dimensi gambar lainnya.

Sebelum mulai mengundang orang untuk mengunjungi halam Facebook, maka perlu menambahkan beberapa konten (status) pada Facebook Page. Untuk itu, perlu menambahkan setidaknya beberapa status awal ke Facebook Page. Beberapa jenis status update yang yang akan membantu pertumbuhan bisnis melalui Facebook Page.

Jika tidak mengisinya dengan konten atau status yang tepat. Bahkan, kalau Facebook Page kosong (tanpa konten), maka Facebook Page tidak berpengaruh apa-apa tidak akan mendapatkan banyak keterlibatan. Karena, tidak mempunyai banyak pengikut. Setidaknya, dalam Facebook Pages harus mampu memiliki banyak penggemar sehingga penggemar terlibat dalam usaha pemasaran melalui Facebook Page. 


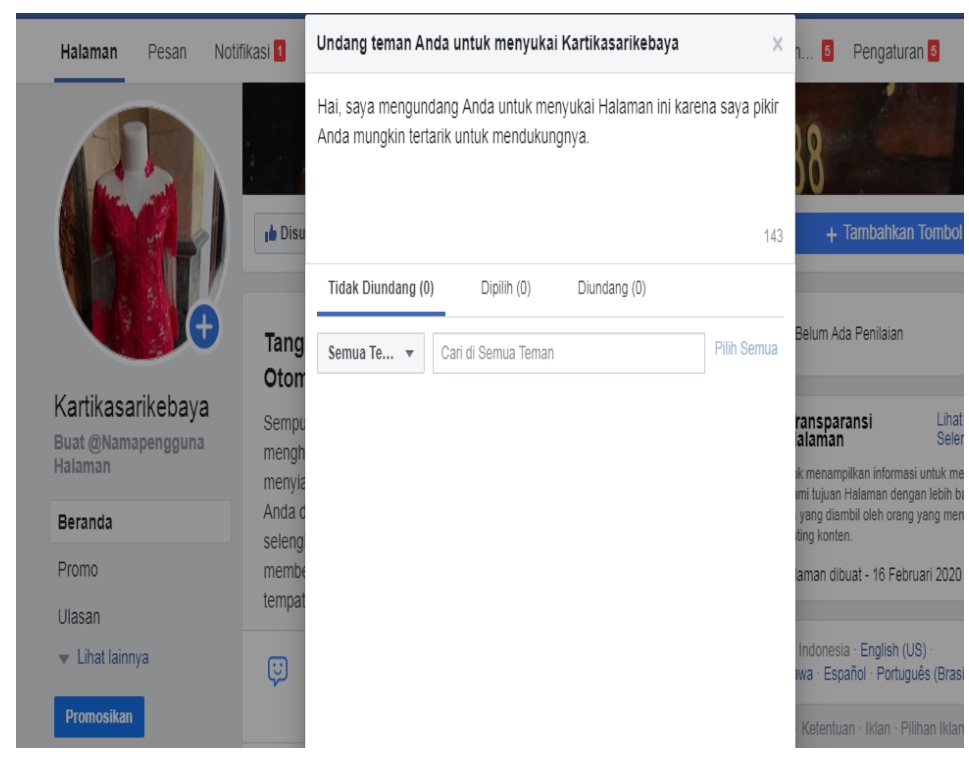

Gambar 4: Undang Teman Facebook Pages

Selanjutnya, tinggal mengundang beberapa orang untuk menyukai Facebook Page pada Gambar. Terdapat beberapa cara yang bisa Anda gunakan untuk menambah fans pada Facebook Page. Semakin banyak mendapatkan banyak like, maka bisnis online ini juga akan semakin tumbuh.

Materi penyuluhan pembuatan facebook Pages ini memuat pembelajaran bagi mitra tentang cara memperkenalkan barang dagangan mereka kepada khalayak sasaran Hasil yang diperoleh dari adanya kegiatan penyuluhan ini adalah bahwa mitra dapat memahami dengan baik materi penyuluhan yang diberikan. Mitra memiliki antusiasme yang tinggi untuk belajar mengenai pemasaran online ini.Kami juga akan memantau perkembangan akun pemasaran online yang sudah mereka buat untuk melihat seberapa banyak postingan yang mereka buat mengenai barang dagangan mereka. Selain itu, kami juga bermaksud mengetahui permasalahan yang mungkin mereka hadapi dalam menerapkan metode pemasaran online ini dan berupaya mengetahui pula sejauh mana efektivitas cara berdagang melalui pemasaran online ini dalam meningkatkan jumlah dan omzet penjualan jasa produksi UKM "Kartika Sari Kebaya"

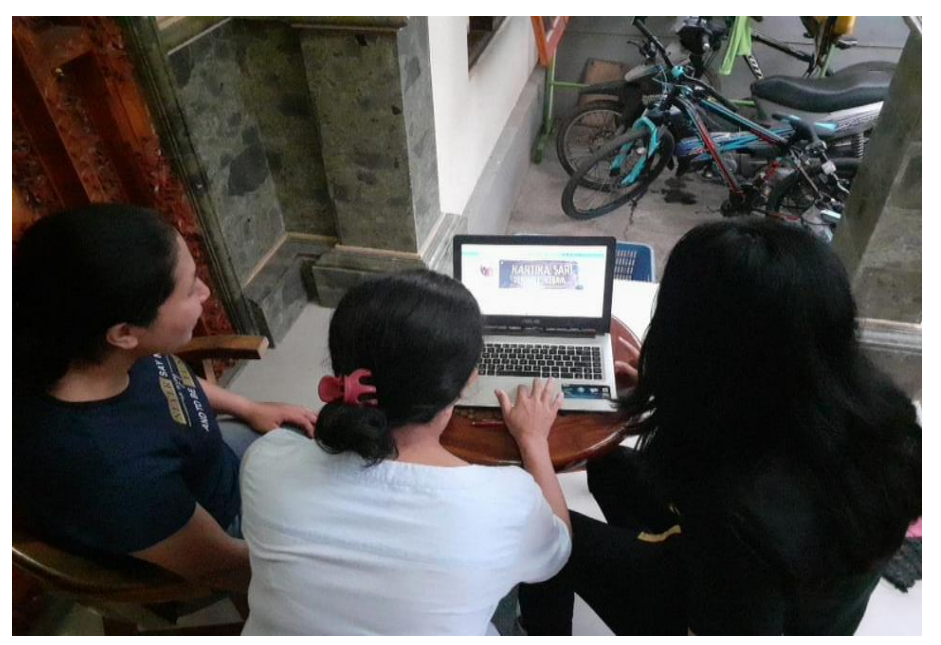

Gambar 5 Kegiatan Pelatihan Facebook Pages yang Dilakukan Dengan Mitra 


\section{Diskusi}

Diskusi dilakukan untuk mengetahui perkembangan peserta setelah melakukan proses pelatihan dan mengaplikasikan materi yang di ajarkan sehingga dapat mengetahui manfaat yang dirasakan. Peserta diberikan tugas yang berkaitan dengan pelatihan yang telah dilakukan sebelumnnya. Berdasarkan hasil diskusi yang telah dilakukan, kegiatan pengabdian masyarakat berupa pelatihan ini mendapat respon yang positif dari peserta. Mereka sangat antusias dalam mengikuti kegiatan tersebut dan merasa lebih terbantu dalam manajemen pemasaran dimana mereka memperoleh pengetahuan baru mengenai cara memasarkan jasa mereka secara online yang diharapkan dapat lebih membantu mereka dalam memperkenalkan produk hasil kreatifitas mereka kepada khalayak ramai dan membantu meningkatkan jumlah dan omzet penjualan serta keuntungan finansial yang dapat mereka raih

\section{Kesimpulan}

Mitra sangat antusias mengikuti seluruh tahap pelaksanaan kegiatan pengabdian, baik dari sosialisasi sampai dengan evaluasi. Pendampingan penggunaan aplikasi facebook media sosial diberikan kepada mitra dengan tujuan agar mitra memiliki pengetahuan dalam menggunakan media sosial dan internet sebagai sarana dalam mempromosikan bidang usahanya. Dan terus menggunakannya secara berkelanjutan serta meningkatkan pendapatan mitra.

\section{Daftar Pustaka}

Kotler P, Armstrong G. 2013. Prinsip-prinsip Pemasaran, Edisi ke-12. Erlangga, Jakarta.

Admin. 2016. Panduan Membuat Facebook Page untuk Bisnis Anda. Artikel. https://elitemarketer.id/engagement/panduan-membuat-facebook-page-untuk-bisnis-anda/. (diakses tanggal 26 Maret 2020).

Berlianti. 2017. Kemandirian Perempuan Melalui Keterampilan Menjahit. Jurnal Abdimas. Kesejahteraan Sosial FISIP USU, Sumatera Utara 